\begin{tabular}{|l|l|l|}
\hline & GOMAL UNIVERSITY \\
JOURNAL OF RESEARCH & \\
\hline
\end{tabular}

\title{
PERCEPTIONS OF TEACHER EDUCATORS AND PROSPECTIVE TEACHERS ON THE ASSESSMENT LITERACY AND PRACTICES
}

\begin{tabular}{|c|c|}
\hline $\begin{array}{r}\text { Sa } \\
{ }^{1} \text { Assistant Professc } \\
{ }^{2} \text { Assistant Professor, } \\
{ }^{3} \text { Assistant Professo }\end{array}$ & $\begin{array}{l}\text { Hussain }{ }^{1} \text {, Muhammad Idris }{ }^{2} \text { \& } \text { Zarina Akhtar }^{3} \\
\text { enter for Education and Staff Training, University of Swat, Pakistan } \\
\text { lartment of Education, Abdul Wali Khan University Mardan, Pakistan } \\
\text { epartment of Education, International Islamic University Islamabad }\end{array}$ \\
\hline ARTICLE INFO & ABSTRACT \\
\hline $\begin{array}{l}\text { Keywords: } \\
\text { Prospective Teachers, } \\
\text { Classroom Assessment, } \\
\text { Assessment literacy, } \\
\text { Assessment Methods, } \\
\text { Assessment Practices }\end{array}$ & \multirow{2}{*}{$\begin{array}{l}\text { This study explores the teacher educators' and prospective teachers' } \\
\text { perceptions regarding classroom assessment literacy and practices. } \\
\text { It specifically aims to respond to questions: 'what teacher educators } \\
\text { and student teachers perceive with regard to classroom assessment, } \\
\text { purposes, approaches, literacy and practices? How many perceptual } \\
\text { differences exist between teacher educators and student teachers on } \\
\text { classroom assessment practices? Through sequential triangulation, } \\
\text { mixed-method research design data were collected over interview } \\
\text { protocols and a Likert design questionnaire. Further, qualitative data } \\
\text { were analyzed through a thematic approach while quantitative data } \\
\text { were analyzed through mean scores and t-test. The results indicated } \\
\text { significant differences in the understanding of classroom assessment } \\
\text { practices of teacher educators and student teachers. Furthermore, } \\
\text { student teachers feel tense due to prevalent assessment mechanisms. } \\
\text { The results also revealed that prevalent assessment approaches fall } \\
\text { short of developing requisite skills among student teachers. Thus, } \\
\text { alternative assessment practices with more students centered and } \\
\text { real-life approaches were recommended for prospective teachers in } \\
\text { classroom situations. } \\
\text { c) @ @ } 9020 \text { Gomal University Journal of Research }\end{array}$} \\
\hline $\begin{array}{l}\text { Article History: } \\
\text { Date of Submission: } \\
\text { 01-12-2020 } \\
\text { Date of Acceptance: } \\
\text { 19-03-2021 } \\
\text { Date of Publication: } \\
\text { 31-03-2021 }\end{array}$ & \\
\hline Corresponding Author & Sajjad Hussain: sajjadhussain@uswat.edu.pk \\
\hline DOI & https://doi.org/10.51380/gujr-37-01-07 \\
\hline
\end{tabular}

\section{INTRODUCTION}

The need for investigating the importance of assessing students' performances to improve their achievement is almost as old as the modern schooling system that has been emerged in aftermath of industrial revolution in 20th century. The assessment has been affirmed as a vital component in professional careers of teachers. It enables them to improve their instructional practices and the learning progress of students (Gotch \& French, 2014; Hussain, Kayani, \& Akhtar, 2018). In this direction, various professional platforms have been actively working to provide a baseline for improvement of pedagogical and instructional knowledge of teachers in classroom assessment. 
American Federation of Teachers (AFT), National Council for Measurement in Education (NCME), and national educational assessment has come up with criteria and yardsticks to measure teacher competency in classroom assessment. These yardsticks are presented in form of seven assessment literacy standards. These standards are comprised of basic knowledge and skills of assessment, assessment methods, data gathering, and use of the assessment results for different purpose, and communication of assessment results to all stakeholders in an educative manner. Further, ethical measures in students' assessment are also important dimensions of these assessment standards (Hussain, 2017). Initially, these standards were used a baseline to enrich field of assessment and evaluation.

In this regard in 2001 at the International Symposium for Assessment, New Zealand, Canada, the United States of America, the United Kingdom, and Australia have committed to work jointly for further promotion of assessment knowledge and skills in their respective countries. In the light of their commitment various joint research projects and individual studies in the field of assessment were conducted where the focus was made on the current assessment standards for in-service and the pre-service teacher education/training. Similarly, the existing assessment standards were also revised according to results of scholarly work done in the field. These standards targeted at the minimum level of proficiency that is indispensable for teachers to effectively engage in assessing student learning (DeLuca, McEwan, \& Luhanga, 2016). Studies on classroom assessment have unearthed parameters that are significant with regard to raising student achievement. Classroom assessment is therefore considered one of the important dimensions of the teacher education and training (Deneen, Brown \& Parker, 2016). In continuation of the importance of assessment for the students' learning Gottheiner and Siegel (2012) promoted the concept of the authentic assessment approaches where the concerned students are involved in applying the assessment procedures by collecting, analyzing and the interpreting students' data through the systematic and the scientific mechanism. These procedures and processes enable students to realize their strengths and areas of improvements.

The concept is parallel to assessment integrated instruction where students learn from assessment tasks that are designed by the teachers and students. Further, Gotch and French (2014) added that collecting reliable and valid information, require the understanding and use of assessment principles which enlighten the cognitions of students and enhance their analytical skills, which includes; assessment, measurement and statistical literacy of teachers as well as of students. The assessment takes place in classrooms having different purposes and the results obtained from assessment are always significant for all the stakeholders whom they use according to their needs and purposes (Hussain, Shaheen, Ahmad, 2019). Teachers use assessment results to measure the effectiveness of the instruction, students' comprehension of contents and skills, grading students, and distinguishing between high and low achievers in classroom. School administration uses it for school audit, teachers' promotions, and future students' in-take and to report to community and top management of institution. Curriculum experts use it to assess the effectiveness of curriculum as reflected in quality and depth of learning experiences of students, contents, and recommended assessment approaches. They use it to make changes in curriculum (Mertler \& Campbell, 2005). The assessment information can be used to assess educational programs and policies (Marzano, 2009).

Last but not the least, parents of students value assessment as means to evaluate their investment in the education of their children and are interested to know about the product in which they are investing. Experts in assessment and measurement believe that assessment is multiple in nature as it is not only used for above-mentioned purposes but can also be used for enhancing students' critical thinking, personality development, motivation and academic achievement (Stiggins, 2005; 
Gotch \& French, 2014). Similarly, Gardner and Gardner (2012) concluded that ultimate purpose of assessment is to improve students' academic performances not just to grade student performances. Furthermore, without assessment, teaching-learning process remains incomplete. The emergence of new concepts like assessment for learning, alternative assessment techniques, self-assessment, peer assessment, performance-based assessment and authentic assessment are the pieces of the evidence in the researcher community where its different uses are empirically proved (Stiggins, 2005; Banda, 2005; Bell \& Ford, 2007; Mussawy, 2009). But the most popular approaches in this category are formative and summative which are commonly used in the classrooms' assessment practices.

Dunn and Mulvenon (2009) summarized the formative assessment approach as it concentrate on the improvement of learning processes with the ultimate target of the effectiveness of the teachers' teaching and students' learning. Further, they advocated that commonly used assessment tools used in formative assessment is; open classroom discussions, students' questioning on teachers' lectures, portfolios, anecdotes, and one-minute tests Electra. The use of these tools depends on the user, if these are used by the teachers' they use to measure the students' understanding, their strengths and improvement areas and if used by the students, they concentrate to measure their performance with their own and with their peers. On contrary, Black and Wiliam (1998) enlarged summative assessment approach where the center of focus is to investigate the level of learned knowledge and skills of students; to grade their performances against pre-determined criteria of judgment which are important from perspective of instructional, academic, and administrative decisions.

\section{Rational of Study}

There are numerous studies that revealed low understanding of assessment concepts and practices. Furthermore, these low assessment literacies are further intensified in designing of assessment tools which leads to low level results of THE students' academic performances that results in lower outcomes for which there are numerous reasons including low aptitude of prospective teachers are relying on their traditional assessment practices. Therefore, this study was designed to explore how the teachers' educators and prospective teachers perceived assessment literacy, practices, and the factors that affect the learning and implementation of assessment in the teacher education.

\section{Research Objectives}

Every research is based on certain objectives, so this research study investigated following research objectives;

1. To investigate teacher educators' perceptions on purposes of the classroom assessment, approaches, literacy, and practices in teacher education

2. To investigate student teachers' perceptions on purposes of the classroom assessment, approaches, literacy, and practices in teacher education

3. To measure the perceptual differences between teacher educators and student teachers on purposes of the classroom assessment, approaches, literacy and practices in teacher education

4. To explore the causes of the differences between teacher educators and student teachers if exist on purposes of classroom assessment, approaches, literacy, and practices

\section{Research Hypotheses}

To investigate the research objectives, the following research hypotheses were formulated from the study; 
1. Teachers have positive perceptions about the purposes of the classroom assessment, approaches, literacy, and practices in teacher education

2. Student teachers have positive perceptions about the purposes of classroom assessment, approaches, literacy, and practices in teacher education

3. There is significant difference between teacher educators and student teacher perceptions about purposes, approaches, literacy, and practices in classroom assessment

\section{LITERATURE REVIEW}

Educational research is incomplete without assessment and evaluation, as it provides baselines to teachers, students, policymakers, parents and all stakeholders of educational outcomes. Holzinger, Lettner, Steiner and Melser, (2020) concentrated on students' perceptions of the concepts of the traditional assessment. The students were found interested in oral assessment and objective type of tests as they viewed these types of the assessments are futuristic in nature and provide reliable results for students' future performances in their respective fields. Traditional assessments are frequent in the field of medical sciences, where standardized assessment tools are preferred to be utilized which are sometimes stressful for students and cause anxiety among them, that's why they like to be assessed through oral assessment and multiple-choice questions. Likewise, Ma (2018) while exploring influences of assessment for learning in students' academic writing found that students like teachers' centered assessment approaches even in assessment for learning. Furthermore, the results of this study elaborated that students are comfortable with teachers' led assessment practices even if it focuses on provision of extensive reading materials to them; they were reluctant about students' led assessment practices their academic writing courses in subject of English.

This study was conducted in Thailand where the role of teacher is more authoritative and the same were enzyme by their students, furthermore, the students were also aware of the benefits of students led assessment practices but they were less interested for taking the responsibility of assessment. On the contrary to students' perceptions about assessment teachers stand at a unique pole on the use of assessment practices while measuring students' performances. Gardner and Galanouli (2016) arguably concluded that teachers' perceptions about the assessment tools and procedures are mostly based on the dependability of assessment. They consume valuable energies on the accuracy, fairness, reproducibility, and fitness of purpose. These perceptions of teachers are not free from their professional role's compulsions, which motivate them to ensure concept of academic accountability to all the stakeholders including students. Experts like Hussain, (2017); Zulaiha, Mulyono and Ambarsari, (2020) discussed the teachers' assessment understanding and literacy and its role in the improvement of students' academic performances. They concluded that teachers have an average level understanding on the principles and procedures of assessment but they are struggling in designing of assessment while Zulaiha, Mulyono, and Ambarsari, (2020) found the gap between the teachers' understanding of assessment and their classroom assessment practices.

Furthermore, according to Hussain, Idris, and Akhtar (2019) teachers' assessment beliefs are the significant determinants of their assessment practices, the sophisticated assessment beliefs lead towards authentic assessment practices that ensure the credibility of students' assessment results, on the contrary, traditional and non-sophisticated assessment results in traditional authoritative assessment practices associated with students' test anxiety (Ahmad, Hussain, \& Khan, 2018), depression, declining students' motivation, and low academic performances of students external examinations. All these studies are based on the scientific models of measurement and assessment where the quantification through paper and pencil tests are accepted as the symbol of students' performances (Gipps, 1994). This model was replaced by the qualitative and performance-based 
assessment models where more focus was given to students performance in the field and absolute quantification (Hager, \& Butler, 1996) was subsidized which has provided the foundation for the autonomy of students in assessment and its related decisions which can be seen in the form of the concept of self-assessment, peer-assessment, and supervisor and like more. This shift further demanded more knowledge and understanding from all stakeholders of educational assessment of students. Thus, it was vital to investigate teachers' and students' perceptions about classroom assessment.

\section{RESEARCH METHODOLOGY}

The research design adopted for study was sequential triangulation from mixed-method research designs following constructivist paradigm. All the teacher educators and student teachers enrolled in B. Ed Hons at 17 public universities of Khyber Pakhtunkhwa, Pakistan constituted the target population of the study. Through a simple random sampling technique a sample of 36 teacher educators and 125 student teachers were generated. Two instruments were used in data collection process. A Likert scale questionnaire was used to measure the teacher educators and prospective teachers' perceptions on assessment. Questionnaire developed was pilot tested at The University of Swat. Students and teachers of B. Ed Honors at the University of Swat constituted the sample for piloting. The reliability co-efficient of Likert scale questionnaire used for data collection from teacher educators and students was found to be .827 . This reliability co-efficient according to Grifee (2012) is higher and enough to ensure reliability of data collected over this questionnaire. There were 20 items on questionnaire which was divided into four components: a) purposes of assessment, b) assessment approaches, c) assessment literacy d) classroom assessment practices. Data were collected from respondents of study through self-visits to departments and over google form.

The same contents were used in google form and manual questionnaire. Sixty-five respondents respond on google form and the remaining ninety-six respondents responded on manual personal visits. However, interview research protocols were adopted from the work of Harris and Brown (2009). There were thirteen interview questions covering different aspects of the assessment. The study followed all the procedures necessary for conducting the research study systematically on reach the conclusion of the study. Furthermore, the research interview protocols were used on the prior permission of the authors. Fifteen respondents of the study were interviewed, among those fifteen three were interviewed on WhatsApp, four on telephonic calls, and the remaining eight interviews were conducted face-to-face with the respondents of the study. The data were analyzed through mean scores, standards deviations, and independents sample t-tests. Furthermore, the gender-wise comparison was also made through independent sample t-tests. Similarly, the data obtained from the interviews were analyzed through the Q sort method. All the interviews were narrated first then these interviews were coded and finally major themes were derived from the codes.

\section{RESULTS OF STUDY}

First of all, the demographic information of the respondents of the study were presented which include: respondent nature, sex, teaching experience, age, qualification, and the semester in which they studied. The results of this study provided significant information about the research phenomena under consideration in order to reach the conclusion more comprehensively. Their percentage was calculated and presented in following tables. Moreover, the questionnaire data were analyzed through mean scores, standard deviation, and independents sample t-tests. The mean scores of the respondents of the current study were analyzed using the following criteria of score divisions: 
Table 1

Mean Scores of Respondents

\begin{tabular}{lccc}
\hline \multicolumn{1}{c}{ Options } & \multicolumn{3}{c}{ Mean Scores Range } \\
\hline Always/strongly agreed & 5.00 & to & 4.51 \\
Most of the times/agreed & 4.50 & to & 3.51 \\
Sometimes/undecided & 3.50 & to & 2.51 \\
Rarely/disagreed & 2.50 & to & 1.51 \\
\hline Not at All/Strongly disagreed & 1.50 & to & 1.00 \\
\hline
\end{tabular}

Table 2

Respondents' Sex and Teaching Experience, Training in Assessment

\begin{tabular}{lccccc}
\hline Respondents & Frequency & Sex & Frequency & Teaching Experience & Frequency \\
\hline Teacher educators & 36 & Male & 108 & 0 to 5 years & 17 \\
Students & 125 & Female & 53 & 6 to 10 & 16 \\
\hline Training & Nil & & & 11 to 20 & 03 \\
\hline
\end{tabular}

The sample that responded to questionnaires comprised $22 \%$ teacher educators and $78 \%$ students. There were $67 \%$ male and $33 \%$ female respondents, having teaching experience to varying degrees. Teacher educators with teaching experience up to five years comprised of $47 \%$ and $44 \%$ had six to ten years and only eight percent had 11 to 20 years of teaching experience. All the respondents were of the view that they had no in-service training in assessment. Furthermore, the teaching experience was limited to teacher educators as all students of B.Ed had no prior teaching experience.

Table 3

Respondents' Qualification, Age and Semester in which they Study

\begin{tabular}{lccccc}
\hline Qualification & Frequency & Age & Frequency & Semester Students & Frequency \\
\hline Undergraduates & 125 & 17 to 24 & 104 & 1st and 2nd & 41 \\
Masters & 2 & 25 to 30 & 21 & 3rd and 4th & 38 \\
M. Phil & 23 & 31 to 35 & 24 & 5th and 6th & 32 \\
\hline PhD & 11 & 36 to 46 & 12 & 7th and 8th & 14 \\
\hline
\end{tabular}

Table 2 illustrates qualification, age, and students' semesters in which they studied. $78 \%$ of the respondents had undergraduate, $1.2 \%$ had Masters, 14\% had M.Phil/M.S and seven percent had Ph.D. qualification. There are $54.6 \%$ respondents in age interval of 17 to $24,13 \%$ in 25 to $30,15 \%$ in 31 to $35 \& 7 \%$ in 46 to $46 y$ ears. 1 st $\& 2^{\text {nd }}$ semester student made $33 \%, 3^{\text {rd }} \& 4$ th-semester students are $30 \%, 5$ th and 6 th semesters students are 26 and 7 th and the 8th semesters' students are $11 \%$ respectively.

Table 4

Purposes of Assessment in Teacher Education

\begin{tabular}{lccccc}
\hline Statements & Mean & SD & df & $\chi 2$ & Sig \\
\hline To motivate students for academic experiences & 3.80 & 1.739 & & & \\
To use for students' grading only & 3.27 & 1.047 & & & \\
To help the teachers to modify the instruction & 4.01 & .859 & 03 & 32.09 & .000 \\
To provide foundation for effective teaching & 3.98 & .952 & & & \\
Classroom tests increase students' anxiety & 3.29 & 1.315 & & & \\
\hline Cumulative scores of "Purposes of assessment" & 15.719 & 1.8008 & & & \\
\hline
\end{tabular}


Table 3 shows the mean scores of the respondents on purposes of assessment. The majority of the respondents were of view that most of time assessment is used for student academic experiences, modifying instruction, and it provides foundation for effective teaching (mean scores were 3.80, 4.01, and 3.98 respectively). Similarly, mean scores of 3.27 and 3.29 respectively showed that the majority of the respondents were of opinion that assessment is sometimes used for grading and sometimes it causes anxiety on classroom tests among students. Chi-square value of 32.09 with a value of .ooo reflected that respondents have a positive attitude towards purposes of assessment. To conclude, majority of respondents opined that motivating students for academic experiences, adjusting classroom instruction and uses of assessment data for teaching is important purpose of assessment.

Table 5

Teacher and Students Perceptions on "Purposes of Assessment"

\begin{tabular}{llcccccc}
\hline & Respondents & $\mathrm{N}$ & Mean & SD & MD & t-value & Sign \\
\hline Purposes of & Teacher educators & 36 & 16.0320 & 1.65459 & 1.3986 & 4.328 & .000 \\
Assessment & Student teacher & 125 & 14.633 & 1.88801 & & & \\
\hline
\end{tabular}

The above table gives a comparison of perceptions of teacher educators and students on purposes of assessment. The mean score of teacher educators (16.032) is higher than the students' mean score (14.633). The mean score difference is 1.3985 and the t value is 4.328 which is significant at .ooo level. These results conclude that teacher educators have highly positive perceptions of the purposes of classroom assessment than the students. Data collected from interviews of teacher educators and students reveals that there are general and specific purposes of the assessment. The majority of respondents were of the opinion that the general purposes of assessment are measuring students learning outcomes, students' grading, identifying the strengths and weakness, and enhancing the effectiveness of instructional quality. Four respondents were of the view that the general purpose of the assessment is to promote or retain the students according to their performances, while the three respondents considered the assessment as a part of the teachinglearning process. Furthermore, they were of the opinion that without the assessment education is incomplete.

One of the major differences that were uncovered in the findings was teacher educators' viewing assessment as having multiple purposes whereas students considering "grading" as only purpose of assessment. However, on question of specific purposes of assessment, the majority of teacher educators were of opinion that it depends on situation where assessment takes place. Moreover, the nature of questions determines purpose of the assessment. Teacher educators and students also differed in their perceptions of the general purposes of assessment. Students considered that there is only one purpose of assessment and that is the student grading, while teacher educators revealed that there are multiple purposes of the assessment such as students grading, improving instructional quality, identifying the students' strengths and weakness. Conversely, the specific purpose of assessment was based on situation and nature of inquiry for which assessment takes place.

\section{Table 6}

Assessment Approaches and its Usages in Classroom in Teacher Education

\begin{tabular}{lccccc}
\hline Statements & Mean & SD & df & $\chi 2$ & Sig \\
\hline Formative assessment is productive & 4.05 & 1.094 & & & \\
Teacher made tests vs standardized tests & 3.70 & .948 & & &
\end{tabular}




\begin{tabular}{lccccc}
\cline { 5 - 6 } Assessment support teachers' teaching & 3.75 & 1.013 & 03 & 59.17 & .000 \\
self-assessment is better than what teachers do & 3.27 & 1.336 & & & \\
Peer assessment develop assessment skills & 3.58 & 1.110 & & & \\
\hline Cumulative "Assessment approaches" & 15.48 & 2.4482 & & & \\
\hline
\end{tabular}

Table 5 illustrates assessment approaches used in classroom assessment. Mean scores of 4.95, 3.70, 3.75 , and 3.58 reflect that majority of the respondents agreed that assessment during the class is better than assessment taking place at end of a class. Teacher-made tests were more productive than standardized tests, formal assessments more useful than informal assessments, and peer assessment practices more productive for students' assessments. Furthermore, the majority of the respondents were undecided on the statement of "Students self-assessment is better than what teachers do." The chi-square value of 59.17 with value .ooo supported these results. To conclude, respondents favored formative assessment practices, teacher-made tests, and formal assessment practices.

\section{Table 7}

Teacher and Students' Perceptions on “Assessment Approaches”

\begin{tabular}{llllclll}
\hline & Respondents & $\mathrm{N}$ & Mean & SD & MD & t-value & sign \\
\hline Assessment & Teacher educators & 36 & 15.71 & 2.99922 & .28871 & .622 & .535 \\
approaches & Student teacher & 125 & 15.42 & 2.27514 & & & \\
\hline
\end{tabular}

Table 6 reveals perceptions of teacher educators and students on assessment approaches used in the assessment. The mean differences results show that .289 with an at-value of .622 were not significant. In sum, the results show that there was no significant difference between the teacher educators' perceptions and students on assessment approaches used in classroom assessment in study.

\section{Table 8}

Assessment Literacy of Students and Teacher Educators

\begin{tabular}{lcc}
\hline Statements & Mean & SD \\
\hline Students' assessment knowledge is indispensable for teachers & 4.25 & .742 \\
Surprise assessment is fair and ethical & 3.78 & 1.071 \\
Written feedback is more valuable for students than verbal feedback & 3.70 & 1.030 \\
Assessment is equivalent to classroom tests & 3.94 & 1.166 \\
Assessment is to certify students and promote to next level & 2.85 & 1.256 \\
\hline Cumulative mean scores of "Assessment literacy" & 16.241 & 2.25567
\end{tabular}

Table 7 gives the assessment literacy with the mean scores of 4.25, 3.78, 3.70, and 3.94, reflecting the majority of respondents agreeing that assessment knowledge is necessary, surprise tests are fair and ethical, written feedback is productive and that assessment is equivalent to test. Also, a mean score of 2.85 shows that majority of respondents were uncertain whether the assessment is only used to grade students and promote them to next level. based on these results it is concluded that assessment knowledge and skills are important for teachers and that written feedback is more effective than verbal feedback. furthermore, calling surprise assessment fair and ethical, and considering assessment test same thing reflects gap in respondent knowledge since such approaches are considered unfair and unethical in certain academic circles. also, knowledge gap comes forth among respondent since test \& assessment are not conceptually equal and in practice. 
test is a limited tool to measure the student performance on given metric and is not equivalent to assessment.

\section{Table 9}

Teacher and Students Perceptions on "Assessment Literacy"

\begin{tabular}{lllccccc}
\hline & Respondents & $\mathrm{N}$ & Mean & SD & MD & t-value & sign \\
\hline Assessment & Teacher educators & 36 & 16.304 & 2.36910 & .2817 & .659 & .511 \\
literacy & Student teacher & 125 & 16.022 & 1.81975 & & & \\
\hline
\end{tabular}

Table 8 reflects the comparison of perceptions of teacher educators and students on assessment literacy. The difference is not significant as shown by mean difference of .2817 and t-value .659. Results illustrated no significant evidence that there is difference in perceptions of respondents on assessment literacy. Teacher educators and students were asked in the interview about four statements on assessment aim to measure their understanding of assessment and were asked that what it means to them; majority of teacher educators appeared to be literate on this parameter as they correctly identified the assessment aims. The same was not true for student respondents. The statements were: 1) what does this statement mean to you: "Assessment keeps schools honest and up to scratch"? 2) What does this statement mean to you: "Assessment determines if a student meets a qualification standard"? 3) What does this statement mean to you: "Assessment helps students improve their learning"? 4) What does this statement mean to you: "Assessment is the unfair to students"? After each question, the respondents were asked to share the extent to which they agreed with the statement? All teacher educators and students agreed with the statements up to the great extent except on the fourth statement on which all the respondents recorded their disagreement.

\section{Table 10}

Teacher Educators and Students Perceptions on Classroom Assessment Practices

\begin{tabular}{llll}
\hline Statements & $\mathrm{N}$ & Mean & $\mathrm{SD}$ \\
\hline Multiple choice questions are appropriate for all sorts of assessment & 161 & 3.96 & 1.169 \\
Essay type questions are appropriate for all sorts of assessment & 161 & 3.76 & 1.303 \\
Portfolio assessment methods are appropriate for all assessment & 161 & 3.48 & 1.019 \\
Classroom observation is more productive than questioning & 161 & 3.45 & 1.313 \\
Classroom discussion is more productive than student presentations & 161 & 3.21 & 1.153 \\
\hline Cumulative mean scores "classroom assessment practices" & 161 & 15.28 & 3.5427 \\
\hline
\end{tabular}

Table 9 reveals that the perceptions on classroom assessment practices had mean scores of 3.96 and 3.76 respectively suggesting that majority of teacher educators agreed that MCQs and essay type questions were appropriate tools for assessment. However, the means scores of 3.45 and 3.21 reflected that the respondents e were not certain whether the classroom observation and the discussions were more productive than questioning and students' presentations. To conclude, the results point that teacher educators and students favored MCQs and essay-type tests in classroom assessment.

\section{Table 11}

Teacher and Students Perceptions on "Classroom Assessment Practices"

\begin{tabular}{llcclccc}
\hline & Respondents & $\mathrm{N}$ & Mean & SD & MD & t-value & Sign \\
\hline C-assessment & Teacher educators & 36 & 13.37 & 3.3833 & -2.4597 & -3.824 & .000 \\
practices & Student teacher & 125 & 15.83 & 3.4058 & & & \\
\hline
\end{tabular}


As Table 10 shows, there is a significant difference between the perceptions of teacher educators and students on classroom assessment practices. Mean difference of -2.4597 shows higher mean scores of students than teacher educators with a significant difference and t value of -3.824 . This shows that students had positive perceptions of above-mentioned classroom assessment practices compared with teacher educators. Thus, the findings show that students favored MCQs and essay types classroom assessment tools over portfolio, classroom discussion, questioning, and students' presentations. Interviews from teacher educators and students revealed that the majority of teacher educators practiced classroom tests, class presentations, and paper-pencil tests (mid/final term examinations). Furthermore, some of the respondents were of the view that they practiced classroom discussions, interviews/viva, and sometimes experimentations. The majority of the respondents revealed that students could also be assessed through home assignments, objective, and subjective type tests, observational techniques, performance-based assessment and through students' portfolios. Similarly, on question which assessment method was best among all, teacher educators and students shared different opinions. Some teacher educators viewed performancebased valuations as better while others favored objective-type tests and standardized assessment tools.

However, one respondent was of the opinion that appropriateness of any assessment tool depends on the nature of respondents, purpose, time, and other factors. On other hand, students shared that classroom tests, presentations, assignments, examinations, and major classroom assessment practices were the predominant modes that their teachers followed in class. They also shared that the best method of assessment was assignment and classroom tests. Some students were also of the opinion that there was no best assessment method as all were the sources of tension and anxiety for them. Based on the results extracted from interviews, it comes forth that there are differences of opinion on assessment methods and approaches between teacher educators and students. Major classroom assessment methods according to teachers are classroom tests, presentations, and paper-pencil test although they recommended that performance-based, standardized assessment tools and objective type tests were also appropriate. On the contrary, students suggested assignment and classroom tests as better approaches to assessing learning in classrooms.

\section{DISCUSSIONS}

Results of the study illustrate that teacher educators and students differed in their perceptions on purposes of assessment. However, some students considered that assessment is only to grade the performances of students. Teacher educators believed that modifying instruction, identifying the strengths and weakness of students, helping to overcome their learning difficulties and students' promotion and retention at the classroom level are other purposes of assessment. These results are similar to the results of Bell and Ford (2007) whose results indicate that assessment is multipurpose, it is not limited to rank, pass, or fail students but it can directly contribute to students' learning outcomes. Furthermore, the results of Harris and Brown's (2009) study also supported the results. Results of study showed that majority of respondents favored formative assessment, peer assessment, teacher-made tests, and formal assessment then summative assessments, teacher assessment, standardized tests, and informal assessment practices. On the contrary, the formative assessment is more productive in raising students learning outcomes as it provides opportunities to teachers to give immediate feedback to students that becomes a significant factor in enhancing effectiveness in teaching-learning processes (Stiggins, 2005: Popham, 2011). But standardized tests are strongly criticized in assessment community and different negative effects on students are discussed. 
Similarly, formal assessment practices are liked by the majority of student respondents who align with assessment standards and principles. The results from quantitative results illustrate that both teacher educators and students have the same level of assessment literacy but from interview data it comes forth that assessment literacy of teacher educators is higher than students. These results are not confirmed by results of study of Davidheiser (2013) and Gotch and French (2014) that investigated teacher assessment literacy and found low assessment literacy of the teachers. Similarly, Popham (2011) revealed that majority of teachers have low level of assessment literacy in most of schools, colleges, and universities. Findings illustrate that majority of the respondents' ideal classroom tests, MCQs, performance-based assessment and students classroom presentation and assignment. Except for the performance-based assessments all the other assessment methods are traditional and the majority of respondents preferred. This finding is in line with the results of Mussawy (2009) who revealed that majority of teachers followed traditional assessment practices and a very small number of teachers practiced alternative and innovative assessment techniques and practices. Also, findings from study of Susuwele-Banda (2005) supported these results which showed that Malawi teachers mostly practiced traditional assessment practices in mathematics classes.

\section{CONCLUSIONS}

Assessment is indispensable in the teaching-learning process as it provides the foundation to the instructional decisions of teachers, motivates students for further learning, and realizes students their strengths and areas of improvement. Furthermore, assessment literacy enables stakeholders to conduct a fair assessment, use suitable assessment tools and inform students through effective feedback mechanisms. Moreover, there was difference in understanding of students and teachers' understanding of assessment, as students' understanding level was less than that of teachers. It was concluded that teachers and students do believe in the effectiveness of traditional assessment tools for all sorts of assessments. They believed that MCQs and essay-type questions (tests) could provide reflective results for all kinds of assessments, they ignored the alternative and modern tools of assessment that portfolio, performances, and authentic assessment tools. One reason for this would be low understanding of these alternative assessment tools and prevailing education system of Pakistan. Teachers were also agreed that classroom presentations, projects, portfolios, assignments, and other kinds of self-regulated assessment are also better options to be used for students' educational assessment. However, the students concluded that their teachers only focus on tests and assignments. The reason was that teachers only do assess students' performance for their grades not for the improvement of students' academic skills neither for their instructional techniques.

\section{Recommendations}

$\checkmark \quad$ Based on the study results and discussions it is recommended for that training or a series of workshops may be arranged with the help of Learning Innovation Division of Higher Education Commission of Pakistan to enhance knowledge and skills of assessment among teacher educators. Teacher educators may handle classroom assessment practices in student-centered manner and involve students in designing assessment activities as per interest.

$\checkmark$ Assessment entails multiple purposes and it could be properly utilized for enhancement of students learning; thus, it is recommended that teacher educators may use students' assessment results in planning the instruction, to obtain desired outcomes giving feedback to students and bringing changes in instruction, the curriculum contents and classroom setting.

$\checkmark \quad$ It is further suggested that teacher educators may prefer to use alternative assessment practices in the students' assessments such as the interviews, anecdotes, and portfolios. 
Furthermore, the subject of classroom assessment in B. Ed Hons and ADE may be taught according to the guidelines provided by Higher Education Commission in the guide books for teachers. For future researchers, it is recommended that the study on "the effects of teacher educators' assessment literacy on their classroom assessment practices" may be conducted.

\section{REFERENCES}

Ahmad, N., Hussain, S., \& Khan, F. N. (2018). Test anxiety: Gender and academic achievements of university students. Journal of Postgraduate Medical Institute, 32(3). 295-300.

Banda, W. J. (2005). Classroom Assessment in Malawi: Teachersâ Perceptions and Practices in Mathematics (Doctoral dissertation, Virginia Tech).

Bell, B. S., \& Ford, J. K. (2007). Reactions to skill assessment: The forgotten factor in explaining motivation to learn. Human Resource Development Quarterly, 18(1), 33-62.

Black, P., \& Wiliam, D. (1998). Assessment and classroom learning. Assessment in Education: principles, Policy \& Practice, 5(1), 7-74.

Davidheiser, S. A. (2013). Identifying areas for high school teacher development: A study of assessment literacy in the Central Bucks School District (Doctoral dissertation, Drexel University).

DeLuca, C., McEwan, D., \& Luhanga, U. (2016). Teacher assessment literacy: a review of international standards and measures. Educational Assessment, Evaluation and Accountability, 28(3), 251-272.

Deneen, C. C., Brown, G. T. L., \& Parker, D. (2016). The impact of conceptions of assessment-onassessment literacy in a teacher education program. Cogent Education, 3(1), 1225380.

Dunn, K. E., \& Mulvenon, S. W. (2009). A critical review of research on formative assessment: The limited scientific evidence of the impact of formative assessment in education. Practical Assessment, Research \& Evaluation, 14(7), 1-11.

Gardner, J. N., \& Gardner, J. (Eds.). (2012). Assessment and learning. Sage Publications, Asian Pacific Pte Ltd, Singapore.

Gardner, J., \& Galanouli, D. (2016). Teachers' perceptions of assessment. The SAGE handbook of curriculum, pedagogy, and assessment, 2, 710-724.

Gipps, C. V. (1994). Beyond the testing: Towards the theory of the educational assessment. The Psychology Press.

Gotch, C. M., \& French, B. F. (2014). A systematic review of assessment literacy measures. Educational Measurement: Issues and Practice, 33(2), 14-18.

Gottheiner, D. M., \& Siegel, M. A. (2012). Experienced middle school science teachers' assessment literacy: Investigating knowledge of students' conceptions in genetics and ways to shape instruction. Journal of Science Teacher Education, 23(5), 531-557.

Griffee, D. T. (2012). An introduction to second language research methods design and data (1st Ed.). California: Tesl-Ej Publications.

Hager, P., \& Butler, J. (1996). Two models of educational assessment. Assessment \& Evaluation in Higher Education, 21(4), 367-378.

Harris, L. R., \& Brown, G. T. (2009). The complexity of teachers' conceptions of assessment: Tensions between the needs of schools and students. Assessment in Education: Principles, Policy \& Practice, 16(3), 365-381.

Holzinger, A., Lettner, S., Steiner, V., \& Melser, M. C. (2020). How to assess? Perceptions and preferences of undergraduate medical students concerning traditional assessment methods. BMC Medical Education, 20(1), 1-7.

Hussain, S. (2017). Relationship of Teacher Educators' Assessment Literacy and Classroom Assessment Practices with their Students' Academic Achievement (Doctoral dissertation, International Islamic University, Islamabad). 
Hussain, S., Idris, M., \& Akhtar, Z. (2019). A Correlational Study on Assessment Beliefs and Classroom Assessment Practices of School Teachers. Journal of Research \& Reflections in Education (JRRE), 13(1). 50-61.

Hussain, S., Kayani, M, M., \& Akhtar, Z. (2018). A coorelational study on teacher educators' assessment Literacy and their students' academic achievement. Pakistan Journal of Education, 35 (3), 59-76.

Hussain, S., Shaheen, N. \&, Ahmad, N. (2019). Teachers' classroom assessment practices: challenges and opportunities to classroom teachers in Pakistan. Dialogue, 14(1), 88-97.

Ma, J. (2018). Student Perceptions of Assessment-for-Learning Practices in an English Academic Writing Course. English Teaching \& Learning, 42(2), 155-183.

Marzano, R. J. (2009). Formative assessment \& atandard-based grading: The classroom strategies series. New York: Marzano Research Laboratory Solution Tree.

Mertler, C. A., \& Campbell, C. (2005). Measuring Teachers' Knowledge and Application of Classroom Assessment Concepts: Development of the. Online Submission.

Mussawy, S. J. (2009). Assessment Practices: Student' Perceptions of Classroom Assessment. Graduate School, Center for International Education (Cie) Department of Education, Policy, Research, And Administration (Epra).

Popham, W. J. (2011). Assessment literacy overlooked: A teacher educator's confession. The Teacher Educator, 46(4), 265-273.

Stiggins, R. (2005). From formative assessment to assessment for learning: A path to success in standards-based schools. Phi Delta Kappan, 87(4), 324-328.

Zulaiha, S., Mulyono, H., \& Ambarsari, L. (2020). An Investigation into EFL Teachers' Assessment Literacy: Indonesian Teacher Perceptions and Classroom Practice. European Journal of Contemporary Education, 9(1), 189-201. 